\title{
Corrigendum: Protein interaction data curation: the International Molecular Exchange (IMEx) consortium
}

Sandra Orchard, Samuel Kerrien, Sara Abbani, Bruno Aranda, Jignesh Bhate, Shelby Bidwell, Alan Bridge, Leonardo Briganti, Fiona Brinkman, Gianni Cesareni, Andrew Chatr-aryamontri, Emilie Chautard, Carol Chen, Marine Dumousseau, Johannes Goll, Robert Hancock, Linda I Hannick, Igor Jurisica, Jyoti Khadake, David J Lynn, Usha Mahadevan, Livia Perfetto, Arathi Raghunath, Sylvie Ricard-Blum, Bernd Roechert, Lukasz Salwinski, Volker Stümpflen, Mike Tyers, Peter Uetz, Ioannis Xenarios \& Henning Hermjakob

Nat. Methods 9, 345-350 (2012); published online 27 March 2012; corrected after print 10 April 2012.

In the version of this article initially published, the names of two authors, Fiona S.L. Brinkman and Robert E.W. Hancock, were incorrectly listed without middle initials. The error has been corrected in the HTML and PDF versions of the article.

\section{Corrigendum: Enhanced photostability of cyanine fluorophores across the visible spectrum}

Roger B Altman, Qinsi Zheng, Zhou Zhou, Daniel S Terry, J David Warren \& Scott C Blanchard

Nat. Methods 9, 428-429 (2012); published online 27 April 2012; corrected after print 27 April 2012.

In the version of this article initially published, the $y$-axis label on a graph in Figure $1 \mathrm{~b}$ was incorrect. The error has been corrected in the HTML and PDF versions of the article. 